\title{
Insight: A co-design approach to understanding energy on a university campus
}

\author{
Aaron Davis a*, lan Gwilt a \\ a University of South Australia \\ *Corresponding author e-mail: aaron.davis@unisa.edu.au
}

\begin{abstract}
:
Cultivating sustainability is a complex concept that shifts beyond the technological focus of eco-efficiency, to engage with social and cultural practices. These social and cultural practices are difficult to define, and are challenging to approach through traditional design processes. A microcosm of this challenge is in reducing the energy consumption of institutional buildings. Here, a tension exists between the building as a technological system, and its performance as a site for human activity. This paper presents a co-design process that brought together a complex group of stakeholders to collaboratively explore understandings, representations, and physicalisations of 'energy consumption'. The results of this process reveal some of the key strengths of the co-design process and provide insights into the ways in which different ontological and epistemological positions can be surfaced through speculative, publicly accessible data visualisation concepts as a catalyst for creative discovery.
\end{abstract}

Keywords: Co-design, sustainability, energy visualisation, data physicalisation, design process

\section{Introduction}

Co-design, like co-creation and co-production is often used as a cover-all term for many different user-engaged processes. The aim of this paper is to present a specific example of a co-design process as it applies to the complex challenge of understanding energy consumption of buildings through occupant behaviours.

In this paper we introduce the challenge of designing strategies to encourage a diverse range of building users to think about and reduce their energy consumption in a shared urban environment such as a university campus. We then present a detailed case study of a co-design process to unpack the various ways in which co-design can help to address the complex socio-technical systems-based questions of sustainability. 


\section{Background}

Buildings are estimated to be responsible for $6.3 \%$ of direct global greenhouse gas emissions, and for $12 \%$ of the emissions associated with electricity and heat production (IPCC, 2014). A number of technological strategies for reducing this consumption have been put forward, including the decarbonisation of the energy supply (Alcott et al., 2012), and improvements in the energy efficiency of building stock (International Energy Agency, 2012). However, the behaviours of the inhabitants of these buildings also have a critical role to play in this narrative. For example, York (2010) highlights the Jevons Paradox (Jevons, 1865) wherein increases in the efficient use of a resource leads to increased demand. A key example of this was described by Slob \& Verbeek (2006) with residents in the Netherlands increasing their use of artificial lighting in response to being provided with more efficient light globes. In response to this, building managers and researchers have made a number of attempts to change occupant behaviour through the presentation of data (Darby, 2006). However, the presentation of objective or rational facts and figures in isolation is not typically successful in catalysing ongoing changes in behaviour (Thaler et al., 2008; Cialdini, 1993). Furthermore, there are examples where the presentation of this data can increase energy consumption (Pierce et al. 2012).

An interesting site for action occurs when building occupants are not directly responsible for energy bills (Darby, 2006). Research in this area typically investigates strategies to stimulate proenvironmental behaviour among groups of non-bill paying end-users (Darby, 2006). Jain et al. (2013) found promising results in encouraging pro-environmental behaviours by changing the units in which information is presented. In particular, using the relatable metric of 'trees' was found to lead to behaviour change while the more common technical, and to many, abstract and difficult to comprehend, metric of kilowatt-hours (kWh) did not (Jain et al., 2013). While this may appear to suggest changing the units that are used in live feedback technologies might drive behaviour change, the relationship with behaviour is more complex. There are a wide variety of theories of behaviour change that are applied across a range of disciplines. Some of the key behaviour change theories have been summarised in table 1 below, with those used to frame this project highlighted.

Table 1. A selection of key behaviour change theories with key references and indicative foci

\begin{tabular}{|c|c|c|}
\hline Theory & Key References & Indicative Focus \\
\hline $\begin{array}{l}\text { Theory of Planned } \\
\text { Behaviour }\end{array}$ & Ajzen (1991) & Individual behaviours in isolation \\
\hline $\begin{array}{l}\text { Transtheoretical Model } \\
\text { of Behaviour Change }\end{array}$ & $\begin{array}{l}\text { Prochaska and Di Climente } \\
\text { (1986) }\end{array}$ & Individual behaviours in isolation \\
\hline Sunk Cost Effect & Arkes and Blumer (1985) & $\begin{array}{l}\text { Resistance to change at an individual } \\
\text { and cultural level }\end{array}$ \\
\hline Tipping Point & Gladwell (2006) & Resistance to change at a cultural level \\
\hline Social Learning & $\begin{array}{l}\text { Reed et al. (2010); Webler } \\
\text { et al. (1995); Rodela (2011) }\end{array}$ & $\begin{array}{l}\text { Individual behaviours within cultural } \\
\text { systems }\end{array}$ \\
\hline $\begin{array}{l}\text { Theories of Social } \\
\text { Practice }\end{array}$ & $\begin{array}{l}\text { Shove et al. (2012); Nicolini } \\
\text { (2012) }\end{array}$ & $\begin{array}{l}\text { Individual behaviours within cultural } \\
\text { systems }\end{array}$ \\
\hline Nudge Theory & Thaler et al. (2008) & $\begin{array}{l}\text { Changing individual behaviours within } \\
\text { cultural systems through default choices } \\
\text { and small interventions }\end{array}$ \\
\hline
\end{tabular}


In this research, the authors have structured the co-design process to incorporate element of Nudge Theory, Social Practice Theory, and the process of Social Learning. Using this approach, both participation in the co-design process itself, and the project outcomes become strategies for behaviour change (Davis \& Andrew 2017).

\section{Methodology}

This research used a blended methodology, with co-design as an overarching methodological tactic. The practice is documented through a Case Study approach (Yin 2009), while also adopting the concepts of Grounded Theory (Glaser \& Straus 2017) and Phenomenology (Goulding 2005) to allow the researchers to document the research in a rigorous, but also self-reflexive way.

Co-design is well established as a methodology for exploring sustainability transitions (Mitchell et al. 2015; Krzywoszynska et al. 2016; Manzini \& Coad 2015; Alexander 2014), and a number of past studies have focused specifically on the role of co-design in energy transitions projects (Jalas et al. 2017; Stevenson et al., 2016; Heiskanen et al. 2010).

In addition, the research was conducted across four stages that broadly aligned with the British Design Council's Double Diamond design framework / process of 'discover', 'define', 'develop' and 'deliver' (Design Council 2004) that are illustrated in Figure 1 below.

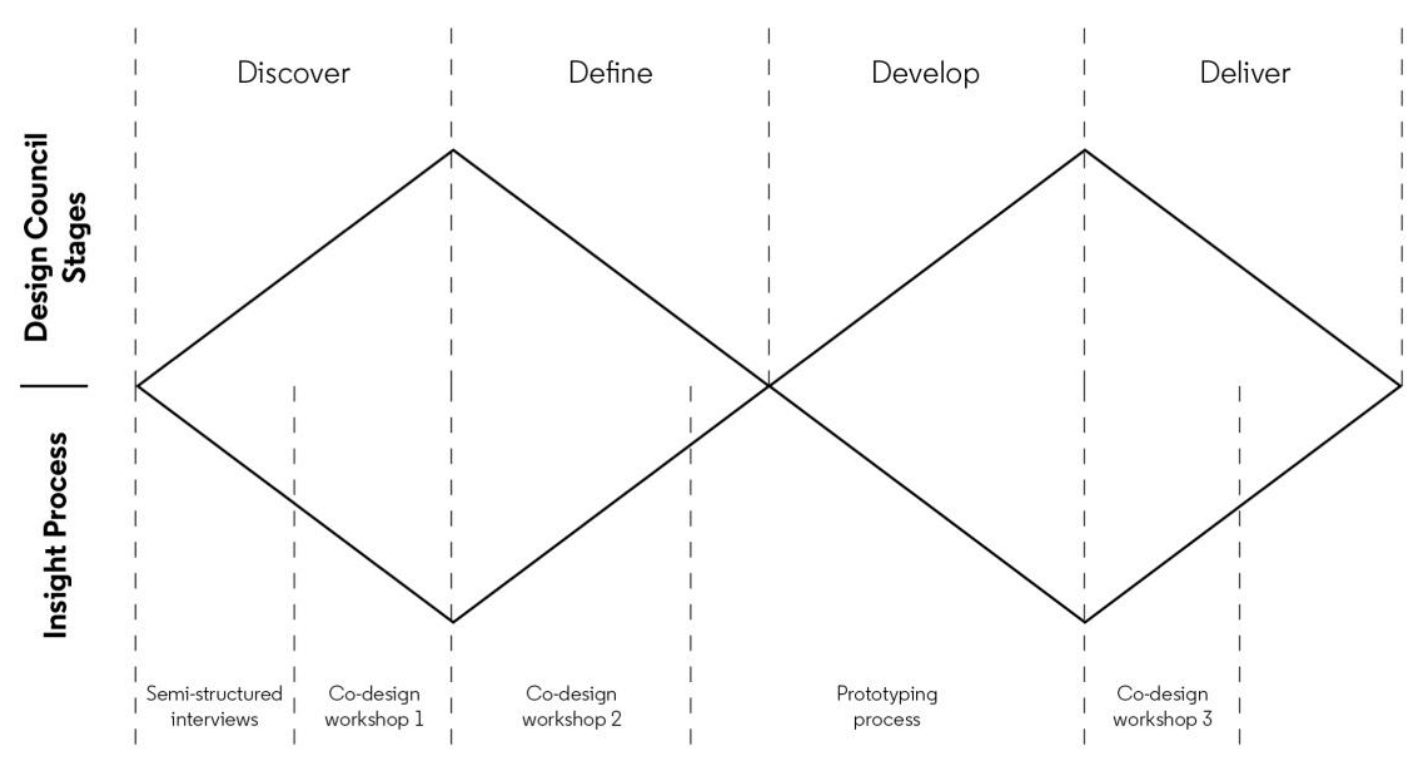

Figure 1. Research process mapped against the Double Diamond Design Process (Design Council 2004)

Participants in the co-design workshops were recruited using the researchers' networks at the University, as well as through an open invitation that was provided to participants in the semistructured interviews and distributed electronically to students and staff. Participation was not based on quotas, but the researchers did aim to engender diversity, targeting specifically: a gender balance, participation of people from a variety of cultural backgrounds including international students and First Nations Peoples, and a balance between staff, student and community participants. The specific and deliberate inclusion of diversity in the co-design process contributed significantly to the findings presented in the next section. 


\section{Co-design processes, results, and discussion}

For clarity and context, the findings from the research activities have been aligned to follow the four stages of the double diamond process; however, it should be noted that there was a significant amount of cross-referencing and reflection between these stages which supported the inductive approach to the research.

\section{1 'Discover'}

In an initial semi-structured interview process, participants were asked to respond to a series of questions through a card-based activity that was loosely based on the cultural probe method (Gaver et al., 1999). Unlike a cultural probe however, the prompts and activities were used to facilitate an iterative and discursive relationship between the participants and the research. The questions broadly explored:

- assumptions about who would benefit from change

- attitudes toward who might be responsible for change, and

- general understandings of energy and energy consumption.

An examples of these cards with sample data is presented in figure 2 below.
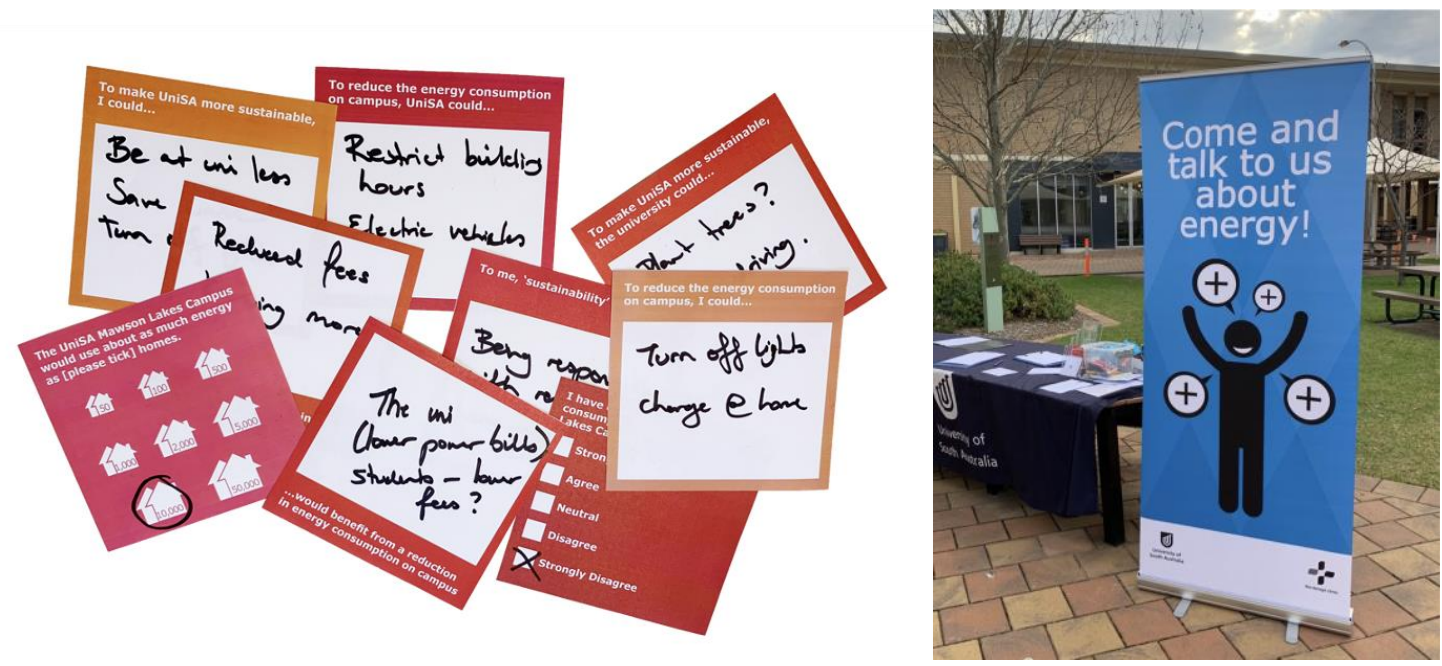

Figure 2. Semi-structured interview card example and data collection stand

When responding to questions about who would benefit from a reduction in energy usage, most initial responses focused on extrinsic benefits, highlighting the University as a key beneficiary, as well as potential extrinsic benefits for students if a reduction in energy use translated to a reduction in fees. Many respondents then began to consider intrinsic benefits and macro-scale benefits with terms like 'everyone', 'all of us', 'the environment', 'climate', and 'the planet' emerging.

Questions about responsibility and control highlighted a general sense of powerlessness. When asked what they could do to make the University more sustainable, and what they could do to reduce energy consumption, many participants responded with 'not much', 'nothing really', 'not a lot', or 'I'm not sure'. Those who did respond overwhelmingly suggested 'turning off the lights' and 'charging devices elsewhere' as ways of saving energy. The notion of 'charging of devices elsewhere' was interesting because of the similarities with the findings of Pierce et al. (2012) who suggested perceived reductions in energy consumption often do not address the root cause. 
When switching to the question of what the University could do, there was a focus again on lighting, banning environmentally damaging products on campus (plastic straws, packaging etc.), and being more active in advocating for 'the environment'. A smaller number of participants highlighted the Heating, Ventilating, and Air Conditioning (HVAC) systems and equipment as issues, as well as energy generation technologies, and building design. These findings are broadly in line with Darby (2006), Pierce et al. (2012), and Jain et al. (2103), particularly that end-users typically had low-levels of understanding of the impact of their energy behaviours.

The first co-design workshop brought together 10 participants to discuss the concept of 'energy'. The primary focus of this workshop was on exploring how different participants understood energy, to gain some insights into opportunities for prompting pro-environmental behaviours.

The question cards from the semi-structured interview process were used as a warmup activity before a group discussion about energy was conducted using five prompt questions:

1. What does 'energy' mean to you?

2. What forms does 'energy' come in?

3. Can 'energy' mean something else?

4. How many different forms of 'energy' are there?

5. What does $\mathrm{CO} 2$ impact mean?

Of particular significance in this part of the workshop were the contributions of members of the First Nations community that brought their cultural understandings of energy to the discussion. It was through their sharing that the ontological and epistemological assumptions of all participants began to be surfaced. A First Nations perspective of 'energy' as 'life' recontextualised the question of energy from a typically scientific paradigm to consider the more human centric understandings of energy.

The final part of the first workshop presented a brief overview of some of the academic literature in this space and looked at a series of existing data representation techniques, dashboards, and communication tools relating to energy. The data representations and tools were then discussed and evaluated in the context of the emergent group understanding of 'energy' to highlight those conceptions of energy that were not present in the existing visualisation and physicalisation examples.

\section{2 'Define'}

A second workshop occurred one week after the first. The facilitators invited the same participants back to continue the discussion about energy as well as a number of people who were not able to attend the first workshop. This resulted in a total of 14 participants in this workshop.

Based on the discussions of the first workshop, three prototyping activities were designed:

1. digital dashboard prototyping

2. storyboarding, and

3. rapid physical prototyping.

In the digital dashboard prototyping activity, the responses focused unsurprisingly on data representation and on communicating information in a visual format. Most prototypes included graphs, and static information displays, however, some featured dynamic or metaphorical representations of energy consumption, including spinning boomerangs and live streamed footage of coal power stations. 
When switching to storyboarding, participants began to explore the concept of the spectacle, as an impactful visual event that causes people to stop and take notice. This idea had not been discussed as a part of the first prototyping activity and added a layer of thought to the overall discussions.

The final prototyping activity provided participants with a range of materials including cardboard, popsicle sticks, pipe cleaners, ping-pong balls, and pegs. Representations of energy included elements of both the first prototyping activity (digital dashboards) and the idea of the spectacle. Example prototypes are presented in Figure 4 below.

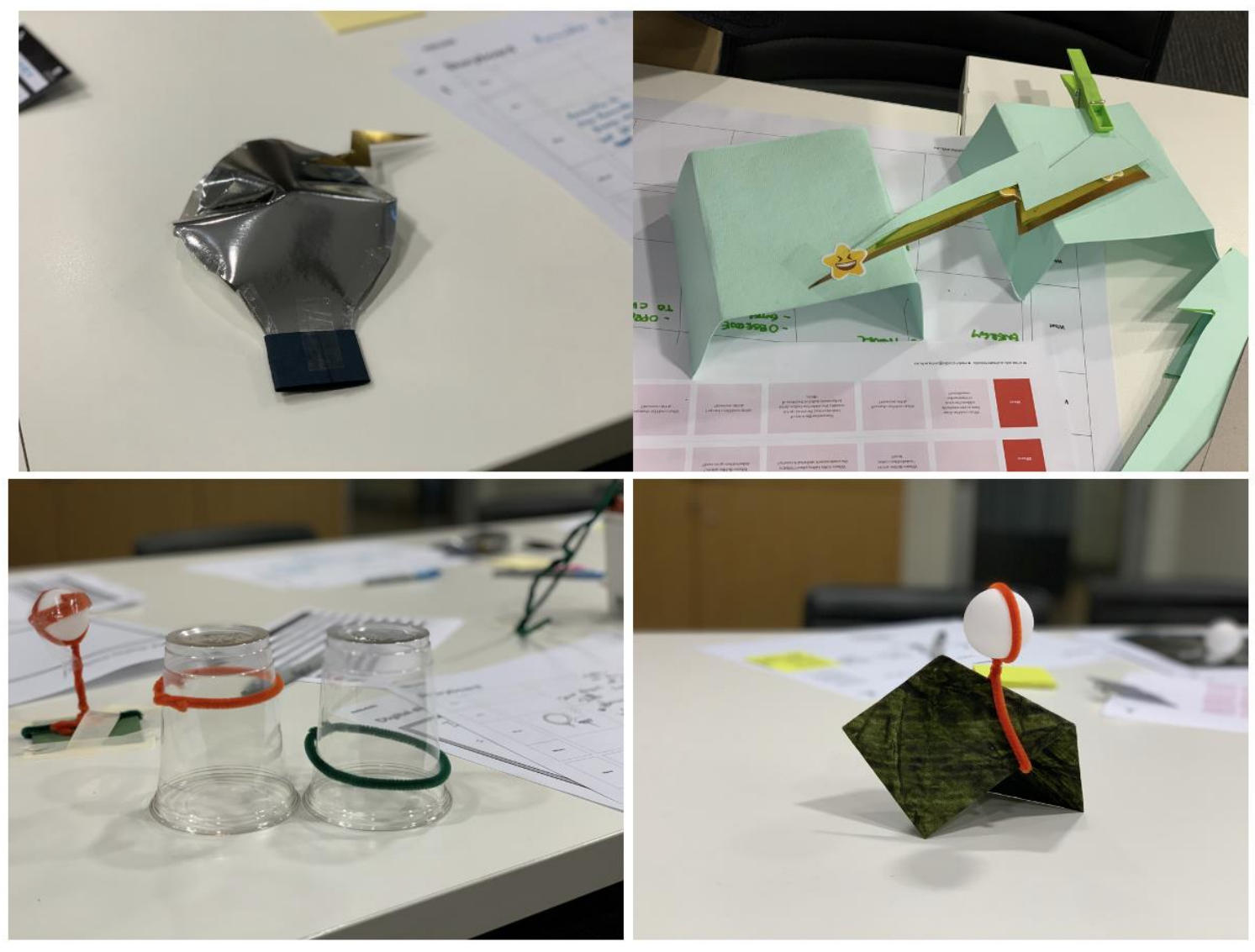

Figure 4: Prototypes for visualising energy usage

Participants engaged in the three prototyping activities in very different ways. The workshop was designed to both support and challenge those from technical as well as creative backgrounds to engage in prototyping in familiar and unfamiliar ways. This created an environment where participants were actively engaging with and learning from the approaches of others, continuing the social learning processes that commenced in the first workshop. The contributions made by the First Nations people at this workshop again added a very different way of thinking about the ideas of spectacle, and metaphors for energy. Culturally specific semiotics were evident in the responses from these participants that lead to a range of discussions, which again facilitated social learning among participants.

\section{2 'Develop'}

Following the second workshop, the researchers reviewed and considered the prototypes that had been described in the workshop and developed them visually into seven more-detailed protypes with the help of two product design students. A selection of these are presented in figure 5 below. 


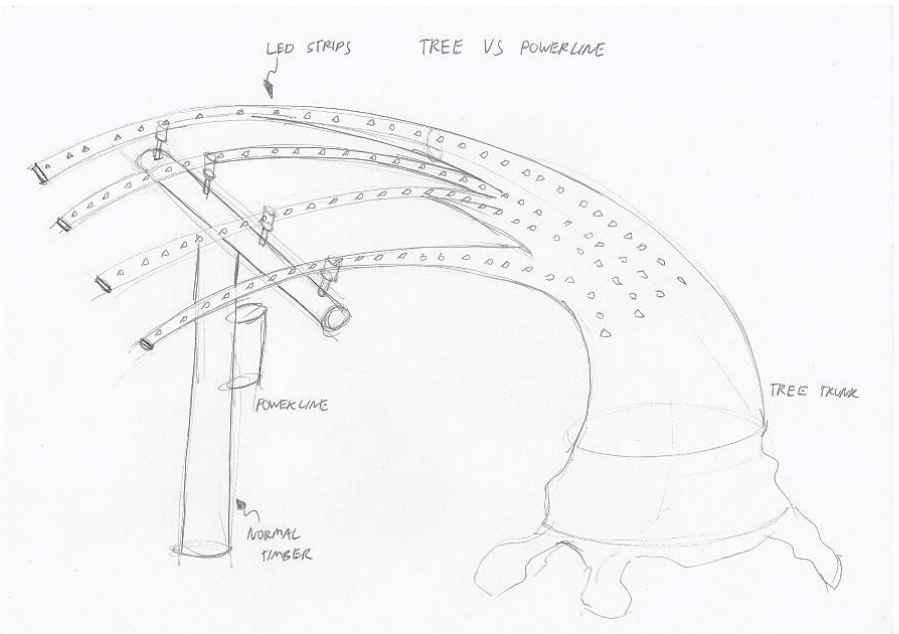

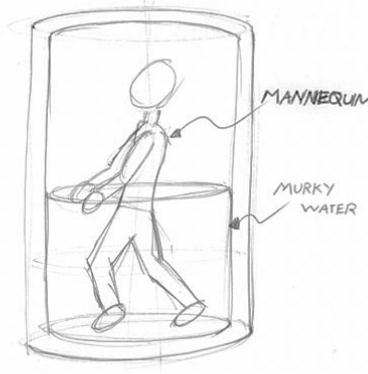

LOW ENERGY USAGE

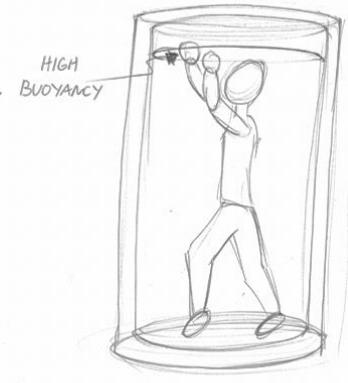

HIGH ENERGY USAGE

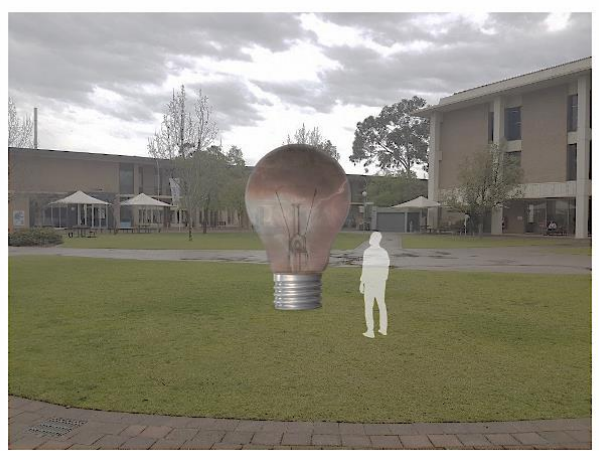

Figure 5: Sample concepts presented for iteration and review

The students had been present at the two previous workshops, allowing them to reflect on their own experiences as part of this process. In the workshop, participants were provided with a prototype review sheet which presented a series of questions about the prototypes and asked them to contribute further to the iteration of the ideas. Examples of this review sheet are provided in figure 6 below. 
match studio

Prototype Development Review

\begin{tabular}{|c|c|c|}
\hline $\begin{array}{l}\text { Concopt: } \\
\text { Foldable seat } \\
\text { revealing power consumption. }\end{array}$ & $\begin{array}{l}\text { Where could you imagine seeing this? } \\
\text { At difforent divisions/ } \\
\text { or sections across } \\
\text { campus. }\end{array}$ & $\begin{array}{l}\text { What might this make people do/think//ool? } \\
\text { I like the idea of } \\
\text { revealing enegy by } \\
\text { peeking und argraind. }\end{array}$ \\
\hline $\begin{array}{l}\text { What do youllike? } \\
\text { The metaphar is good. }\end{array}$ & \multirow{2}{*}{\multicolumn{2}{|c|}{$\begin{array}{l}\text { Improvementsand developments? } \\
\text { The display underground could be cam bined } \\
\text { with othe ideas, such as tug-a-wor of energy, ar } \\
\text { a lightbuib. } \\
\text { The seat could have some kind ot sensor additionally } \\
\text { so something might be revealed when you sit. }\end{array}$}} \\
\hline $\begin{array}{l}\text { What don'tyoullioe? } \\
\text { The main issue conld be vardalism } \\
\text { flow if placed outside? Maybe they } \\
\text { conld be interior? }\end{array}$ & & \\
\hline
\end{tabular}

match studio

Prototype Development Review

\begin{tabular}{|c|c|c|}
\hline $\begin{array}{l}\text { Concopt } \\
\text { Tree into ejuer line }\end{array}$ & $\begin{array}{l}\text { Where could you imagino seing this? } \\
\text { as an out door } \\
\text { sculeture } \\
\text { (large seale) } \\
\text { bronze. }\end{array}$ & 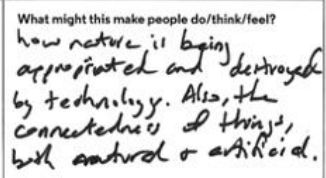 \\
\hline $\begin{array}{l}\text { What doyoulike? } \\
\text { Reminiscect } \& \text { Lovike Bourgeois' } \\
\text { spider iculeture. Sujpests an } \\
\text { anthroescere ds itopia. Surreal. }\end{array}$ & Improvements send dovelopments? & \\
\hline 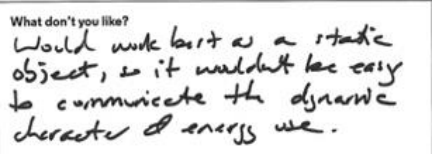 & +2 & 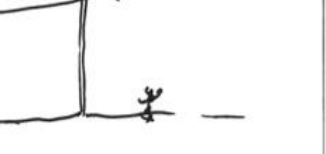 \\
\hline
\end{tabular}

Figure 6: Completed concept review and iteration sheets

At this final workshop, the group engaged in a critical discussion about 'energy' and the relationship between the concepts that had been developed. The First Nations perspective of energy was agreed among the group to have significantly broadened the thinking about the visualisation and physicalisation challenge. In particular, it was seen as being critical in the shift toward understanding and representing energy as a part of the natural environment and as a part of people, rather than being a separate abstract or technological entity.

\section{Reflection, future directions, and conclusion}

Using semi-structured interviews in addition to a literature review at the commencement of this project connected the process with the specific social and cultural context of the university environment that was being investigated. Although the small sample size limited the generalisability of these results, it catalysed a deeper investigation of the specific attitudes and beliefs of those that chose to participate in the co-design process. 
Structuring the co-design process according to the Design Council's Double Diamond (Design Council 2004) allowed the researchers to concentrate on different modes of engagement at different times. The first stage in particular (discover) allowed a conceptual exploration that appears to have been different from the starting points described in much of the previously described literature on this topic. Rather than beginning with the goal of designing a specific behaviour change intervention, the co-design process was able to commence with a discovery phase that explored more broadly the concept of 'energy' from the various epistemological and ontological represented in the assembled group. These conversations in the workshops foregrounded the opportunity for Social Learning through the co-design process.

By allowing participants to consider different ontological and epistemological starting points for the questions that were being raised, the co-design process was able to not only establish an approach based on inductive rather than deductive reasoning, but also to catalyse a significant exchange of knowledge between participants - creating a space within which participants were able to challenge their own a-priori hypotheses. It might be argued that this flexibility exists within any study that uses a Grounded Theory methodology, but the significant value of the co-design workshop in this instance was its ability to create a space and set of participatory activities within which significant Social Learning could take place.

The researchers observed an interesting relationship between the facilitation tools that were used and the outcomes of various processes. Although the co-design process in this project was reliant on not having an a-priori hypothesis, the act of designing the co-design process appears to have functioned in a similar way. This can be seen most strongly in the second workshop, where the materials provided in the prototyping activities steered the results. Here, the researchers worked to mitigate the impact of the activity design influencing the outcomes by including three different types of prototyping that ensured participants were invited to engage with three different formal communication languages. The triangulation of idea generation and communication techniques helped the researchers to use the co-design process to search for underlying themes that were being described between the different prototypes and concepts being communicated, rather than focusing a single production form with its attendant techniques. Despite the emergent link between tools and outcomes, the workshop process was open-ended enough to redirect the attention of the researchers and participants away from the prototypes they thought were going to be the most achievable and realisable. The repeated process of returning to the broader group for discussion and analysis of prototypes and ideas meant that the most successful idea prototypes were those that engaged most closely with the concepts that had been discussed by the collective participants across the three workshops.

The findings relating to the importance of the spectacle, and of individually relatable metrics may have particular relevance within smart city research that is investigating the role of people in the 'smart city' (Komninos 2002; Neirotti et al. 2014; Anthopoulos 2017). More specifically, this research continues to build evidence about the role of people in technologically focused systems (such as Nam \& Pardo 2011; Slob \& Verbeek 2006). It may also demonstrate an opportunity to consider the application of co-design processes to studies that are exploring the significant impact of HVAC systems with research on perceptions of occupant comfort (such as Shaikh et al. 2014).

On a theoretical level, this research has been able to investigate the way in which the co-design process can be used to develop provocations that may lead to later investigation of broader and more generalisable hypotheses. The outcomes from the co-design process have provided a range of opportunities to further explore how energy consumption is communicated, and how people are engaged, particularly in public spaces, with the concept of 'energy'. In particular, the authors see the 
concept of the spectacle as an interesting and novel opportunity to engage broader publics in discussions about energy, and about sustainability more generally. This builds on the work of Manzini and Tassinari (2013) and others, by establishing that co-design processes may be a useful framework for engaging more the community more broadly around complex issues like sustainability.

Another important outcome is the recognition of the significant value that was added to this process through the ability of the co-design process to facilitate exchanges between the participants. The exchanges not only crossed traditional disciplinary boundaries by bringing together a diverse academic group, but also ontological and epistemological boundaries by inviting representatives of the local First Nations community to participate, as well as people from a range of academic, social and international backgrounds. This finding has been taken forward by the authors in further research that is seeking to understand how First Nations peoples engage with the co-design process in contrast to traditional knowledge forming processes.

Finally, perhaps the most important outcome from this research is the exploration of the impact of the design of the co-design process. While the co-design process is often cited as being of value (Davis 2018), the specific exploration and unpacking of where this value is generated in these processes can help plan more impactful co-design processes and experiences.

\section{References}

Ajzen, I. (1991). The theory of planned behavior. Organizational behavior and human decision processes, 50(2), 179-211.

Alcott, B., Giampietro, M., Mayumi, K., \& Polimeni, J. (2012). The Jevons paradox and the myth of resource efficiency improvements. London: Routledge.

Alexander, S. (2014). Disruptive social innovation for a low-carbon world. Retrieved from http://lowcarbonlivingcrc.com.au/resources/crc-publications/research-publications/foregroundpaper-disruptive-social-innovation-low

Anthopoulos, L. G. (2017). The Rise of the Smart City. In Understanding Smart Cities: A Tool for Smart Government or an Industrial Trick? (pp. 5-45). New York, NY: Springer.

Arkes, H. R., \& Blumer, C. (1985). The psychology of sunk cost. Organizational behavior and human decision processes, 35(1), 124-140.

Cialdini, R. (1993). The psychology of influence. New York, NY: William Morrow \& Co. Darby, S. (2006). The effectiveness of feedback on energy consumption. A Review for DEFRA of the Literature on Metering, Billing and direct Displays, 486(2006), 26.

Davis, A. (2019). Understanding the Value of Co-Creation Processes in the Built Environment. Charette, 5(2), 8-21.

Davis, A., \& Andrew, J. (2017). Co-creating urban environments to engage vitizens in a low-carbon future. Procedia engineering, 180, 651-657.

Gaver, B., Dunne, T., \& Pacenti, E. (1999). Design: cultural probes. interactions, 6(1), 21-29.

Gladwell, M. (2006). The tipping point: How little things can make a big difference. New York, NY: Little, Brown and Company.

Heiskanen, E., Hyysalo, S., Kotro, T., \& Repo, P. (2010). Constructing innovative users and userinclusive innovation communities. Technology Analysis \& Strategic Management, 22(4), 495-511.

Intergovernmental Panel on Climate Change (2014). Climate Change 2014: Synthesis Report. Contribution of Working Groups I, II and III to the Fifth Assessment Report of the Intergovernmental Panel on Climate Change. Core Writing Team, R.K. Pachauri and L.A. Meyer (eds.). Geneva, Switzerland: IPCC. 
Jain, R. K., Taylor, J. E., \& Culligan, P. J. (2013). Investigating the impact eco-feedback information representation has on building occupant energy consumption behavior and savings. Energy and Buildings, 64, 408-414.

Jalas, M., Hyysalo, S., Heiskanen, E., Lovio, R., Nissinen, A., Mattinen, M., . . Nissilä, H. (2017). Everyday experimentation in energy transition: A practice-theoretical view. Journal of Cleaner Production, 169, 77-84.

Jevons, W. S. (1865). The coal question: An inquiry concerning the progress of the nation, and the probable exhaustion of our coal-mines. London: McMillan and $\mathrm{Co}$.

Komninos, N. (2002). Intelligent cities: innovation, knowledge systems and digital spaces (Vol. 1).

Abingdon-on-Thames, UK: Routledge.

Krzywoszynska, A., Buckley, A., Birch, H., Watson, M., Chiles, P., Mawyin, J., . . Gregson, N. (2016). Co-producing energy futures: impacts of participatory modelling. Building Research \& Information, 44(7), 804-815.

Manzini, E., \& Coad, R. (2015). Design, when everybody designs: An introduction to design for social innovation. Boston, MA: MIT press.

Manzini, E., \& Tassinari, V. (2013). Sustainable qualities: Powerful drivers of social change. In R. Crocker \& S. Lehmann (Eds.), Motivating Change: Sustainable design and behaviour in the built environment (pp. 217-232). London: Routledge.

Mitchell, V., Ross, T., May, A., Sims, R., \& Parker, C. (2015). Empirical investigation of the impact of using co-design methods when generating proposals for sustainable travel solutions. CoDesign, 12(4), 1-16.

Nam, T., \& Pardo, T. A. (2011). Conceptualizing smart city with dimensions of technology, people, and institutions. Paper presented at the 12th annual international digital government research conference: digital government innovation in challenging times, College Park, MY.

Neirotti, P., De Marco, A., Cagliano, A. C., Mangano, G., \& Scorrano, F. (2014). Current trends in Smart City initiatives: Some stylised facts. Cities, 38, 25-36.

Nicolini, D. E. (2012). Practice theory, work, and organization: An introduction. Oxford, UK: Oxford University Press.

Pierce, J., Fan, C., Lomas, D., Marcu, G., \& Paulos, E. (2010). Some consideration on the (in) effectiveness of residential energy feedback systems. Paper presented at the Proceedings of the 8th ACM Conference on Designing Interactive Systems.

Prochaska, J. O., \& DiClemente, C. C. (1986). Toward a comprehensive model of change. In Treating addictive behaviors (pp. 3-27). Berlin, Germany: Springer.

Reed, M., Evely, A. C., Cundill, G., Fazey, I. R. A., Glass, J., Laing, A., . . society. (2010). What is social learning? Ecology and Society, 15(4), 1-10.

Rodela, R. (2011). Social learning and natural resource management: the emergence of three research perspectives. Ecology and Society, 16(4), 1-18.

Shaikh, P. H., Nor, N. B. M., Nallagownden, P., Elamvazuthi, I., \& Ibrahim, T. (2014). A review on optimized control systems for building energy and comfort management of smart sustainable buildings. Renewable and Sustainable Energy Reviews, 34, 409-429.

Shove, E., Pantzar, M., \& Watson, M. (2012). The dynamics of social practice: Everyday life and how it changes. Thousand Oaks, CA: Sage publications.

Slob, A. F. L., \& Verbeek, P. P. (2006). User Behavior and Technology Development: Shaping Sustainable Relations Between Consumers and Technol (Vol. 20). Dordrecht: Dordrecht: Springer Netherlands.

Stevenson, F., Baborska-Narozny, M., \& Chatterton, P. (2016). Resilience, redundancy and lowcarbon living: co-producing individual and community learning. Building Research \& Information, 44(7), 789-803. 
Thaler, R. H., Sunstein, C. R., \& Leonard, T. C. (2008). Nudge: Improving decisions about health, wealth, and happiness. Berlin, Germany: Springer.

Webler, T., Kastenholz, H., \& Renn, O. (1995). Public participation in impact assessment: a social learning perspective. Environmental impact assessment review, 15(5), 443-463.

York, R. (2010). The paradox at the heart of modernity: The carbon efficiency of the global economy. International Journal of Sociology, 40(2), 6-22.

Author Bios:

Aaron Davis is a Lecturer in Architecture and Research Fellow with a specific interest in the design, facilitation and evaluation of co-design processes. Dr Davis completed his PhD as part of the Cooperative Research Centre for Low Carbon Living, and works at the intersection of design, architecture, sustainability, and behaviour.

Ian Gwilt is Professor of Design at the University of South Australia. Professor Gwilt has worked with a range of participant groups to develop iterative solutions to a range of social and technological challenges using the co-design methodology. Current areas of research include the development of novel information visualization techniques to facilitate the understanding of data for non-specialist audiences.

Acknowledgements: The authors wish to acknowledge all participants in the co-design process, and in particular the contributions of Huy Tran and Nikki Mae Co to the prototyping process.

This research was undertaken on Kaurna Land. In the spirit of reconciliation, the authors acknowledge the Traditional Custodians of country throughout Australia and their connections to land, sea and community. We pay our respect to their Elders past and present and extend that respect to all Aboriginal and Torres Strait Islander peoples. 